\title{
Role of Living Conditions and Socioenvironmental Factors on Chronotype in Adolescents
}

\author{
Prasun Haldar ${ }^{1, \dagger}$, Smriti Debnath ${ }^{2, \dagger}$, Ana Adan ${ }^{3,4}{ }^{\oplus}$, Konrad S. Jankowski $^{5} \oplus$, Dwiptirtha Chattopadhyay ${ }^{6}$, \\ Santi Gopal Maity ${ }^{7}$, Saibal Moitra ${ }^{2,8}$, Paige Lacy ${ }^{9}$ and Subhabrata Moitra ${ }^{9, *}$ (I)
}

1 Department of Biological Sciences, Midnapore City College, Midnapore 721129, India; ssprasun0@gmail.com

2 Department of Pneumology, Allergy and Asthma Research Centre, Kolkata 700029, India; smriti0091@gmail.com (S.D.); saibal.moitra@gmail.com (S.M.)

3 Department of Clinical Psychology and Psychobiology, University of Barcelona, 08007 Barcelona, Spain; aadan@ub.edu

4 Institute of Neuroscience, University of Barcelona, 08007 Barcelona, Spain

5 Department of Psychology, University of Warsaw, 00183 Warsaw, Poland; kjankows@psych.uw.edu.pl

6 Jalpaiguri Institute of Medical Science and Research, Jalpaiguri 735101, India; dwiptirtha@gmail.com

7 Department of Physiology, Uluberia College, Uluberia 711315, India; santigopal.mkmsrm@gmail.com

8 Department of Allergy and Immunology, Apollo Gleneagles Hospitals, Kolkata 700054, India

9 Alberta Respiratory Centre, University of Alberta, Edmonton, AB T6G 2R3, Canada; placy@ualberta.ca

* Correspondence: moitra@ualberta.ca

+ Equal Contribution.

check for updates

Citation: Haldar, P.; Debnath, S.;

Adan, A.; Jankowski, K.S.;

Chattopadhyay, D.; Maity, S.G.;

Moitra, S.; Lacy, P.; Moitra, S. Role of

Living Conditions and

Socioenvironmental Factors on

Chronotype in Adolescents.

Adolescents 2021, 1, 95-107. https:// doi.org/10.3390/adolescents1020008

Received: 17 February 2021

Accepted: 13 March 2021

Published: 1 April 2021

Publisher's Note: MDPI stays neutral with regard to jurisdictional claims in published maps and institutional affiliations.

Copyright: (c) 2021 by the authors. Licensee MDPI, Basel, Switzerland. This article is an open access article distributed under the terms and conditions of the Creative Commons Attribution (CC BY) license (https:/ / creativecommons.org/licenses/by/ $4.0 /)$.

\begin{abstract}
An individual's chronotype, defined as the preference for rest and activity at different times of the day, is linked to several physiological and psychological outcomes. Research on environmental determinants of chronotype has focussed mostly on geographic location, whereas other socioenvironmental determinants have been neglected. We aimed to investigate the association between other previously unrecognized socioenvironmental factors and chronotypes in adolescents. We analysed data of 1916 Bengali adolescents (aged between 13-14 years, 47\% girls). Chronotype was determined by the reduced morningness-eveningness questionnaire (rMEQ), and socioenvironmental factors were identified through a structured questionnaire. Associations were analysed using multinomial logistic regression models. Our findings demonstrated that living in urban areas, the presence of a smoker at home, and higher parental education were associated with a higher evening activity (eveningness), while the use of biomass cooking media (compared to liquefied petroleum gas) and assisting parents in farming were associated with higher morningness in adolescents. This is the first study to identify the association between previously unrecognized socioenvironmental factors and chronotypes delineating the interaction between environment and sleep in adolescents and might help the parents to understand the importance of a proper sleep-activity rhythm of their kids through a comprehensive understanding of their surrounding environment and other factors.
\end{abstract}

Keywords: adolescent; chronotype; socioenvironmental factor; performance; rMEQ

\section{Introduction}

Chronotype or circadian typology is an individual preference for sleep, along with physical and mental activity at particular times of the day [1-3]. Depending on such preferences, people can be divided into three different categories: morning type (early to sleep and early to wake up, and more active during the first part of the day), evening type (late to sleep and late to wake-up, and more active during the latter part of the day), and intermediate-type (in between morning and evening types). Our sleep and activity patterns are presumably governed by biological clocks, which is a synergy between the central (suprachiasmatic nucleus, SCN) and the peripheral (various genes and proteins present in peripheral tissues) clock machinery. Recently, genome-wide association studies (GWAS) have demonstrated an intricately complex genetic makeup that may influence 
the chronotype of an individual [4,5]. However, apart from biological mechanisms, social determinants have also been found to play a significant role in modulating our circadian patterns. While the genetic components of circadian preference are quite stable and rarely alter (some transition can be observed during early adulthood and advanced age), such social attributes often interfere with the genetic components, a perturbation commonly known as social jetlag $[6,7]$. This interaction can attribute to circadian misalignment leading to a disrupted sleep-activity cycle.

In the last two decades, seminal attention has been paid to biological, psychological, and environmental influencers of circadian typology. Among environmental factors, temperature, geographic position (longitude and latitude), and sunshine hours have been found to be associated with chronotype. It has been observed that people living in a warmer climate are more morning oriented than those from colder climates [2,8]. Furthermore, people from a more eastern region within the same time zone are more morning oriented due to earlier sunrise/sunset in the eastern compared to western part of the time zone [9]. Other studies found an association between latitude and chronotype, i.e., people residing near the equator have higher morning activity (morningness) than those residing distantly from the equator [10,11], although one study found the opposite association [12]. Living in rural areas compared to urban areas is associated with higher morningness [13]. Recent evidence suggests that residential proximity to industry, exposure to second-hand smoke (SHS), inappropriate indoor environment, and use of biomass cooking fuel were associated with sleep disturbance [14-23]. Biomass cooking fuel is a well-known risk factor for several chronic respiratory and cardiac diseases [24,25]. In developing countries like India, a large proportion of the population who are at the lower bar in the socioeconomic status does not have a separate kitchen and has to cook inside the living room area using biomass fuel. This produces a very high amount of thick fume which not only hovers in the entire living area but also the vents out to the neighbourhood. Although some of these abovementioned socioenvironmental factors have often been studied in association with health conditions, whether these factors are associated with an individual's sleep and activity preference has not yet been investigated.

In addition to these socioenvironmental factors, certain behavioural factors, such as parental control and parental practice, have also been found to have a potential effect on morningness orientation among adolescents [26-28]. It has been reported that parents' knowledge of health was also associated with sleep quality in children [29]. Sleep behaviour in minors is also influenced by family conditions [28,30], having a sibling [31], and daytime outdoor activities $[32,33]$. It has also been reported that farm children experience more sleep disturbance overall than nonfarm children [34].

Although the abovementioned socioenvironmental, interpersonal, and behavioural factors have been extensively investigated as determinants of sleep, especially in children and adolescents, whether these factors are also associated with chronotype has remained undetermined. In this study, we aim to investigate the relationships between some of these less-studied living conditions and socioenvironmental factors such as exposure to SHS at home, indoor condition (sunlight, ventilation, and cleanliness), cooking media (liquefied petroleum gas or biomass fuel), having a separate kitchen at home, residential proximity to any factory, presence of a smoker at home, parental education, having a sibling, family type, having a pet at home, taking care of the pet, assisting the family in farming, playing outside, and chronotype in adolescents.

\section{Methods}

\subsection{Study Design and Study Population}

In this cross-sectional study, we analysed data from the Prevalence of Asthma and Allergic Diseases among Adolescents (PERFORMANCE) study; detailed information about the study design, participants, and methodologies has been described elsewhere [35]. In brief, we analysed data of 1916 adolescents (aged between 13 and 14 years) who were recruited from 13 randomly selected schools of West Bengal, India. The study has 
been ethically approved by the Clinical Research Ethics Committee of the Allergy and Asthma Research Centre (CREC-AARC), Kolkata, and since the study participants were minors as per Indian law, informed consent was obtained from parents and appropriate school administrations.

\subsection{Instruments}

Chronotype was assessed by a Bengali-validated version of the reduced morningnesseveningness questionnaire (rMEQ) [3]. The rMEQ is composed of five items with a score ranging between 4 and 25 and according to the classical cutoff values, scores $>17$ indicate morningness while scores $<12$ indicate eveningness [36]. Since the cutoffs were determined for the European population, we used 20/80th percentile cut-offs for classification, i.e., participants were categorised as evening, intermediate, and morning types if their total rMEQ scores were $<20$ th percentile, 20 th-80th percentile, and $>80$ th percentile of the total rMEQ score, respectively.

A structured questionnaire was administered to the participants to obtain information about their living conditions and socioenvironmental factors. We considered residential domicile (rural, industrial suburban, nonindustrial suburban, and urban), indoor condition in terms of sunlight, ventilation and cleanliness (poor, adequate, and plentiful), the cooking medium used (liquefied petroleum gas, biomass fuel, or both), having a separate kitchen at home, residential proximity to any factory that emanates dust, fume, and/or noise, presence of a smoker at home, parental education (illiterate, up to primary, up to high school, and college/university), number of siblings (none, one, two or more), family type (nuclear/parents with children or joint/extended family), having a pet at home, taking care of the pet, assisting the family in farming, and playing outside.

\subsection{Statistical Analyses}

The sample size for this study was estimated for the main objective of the PERFORMANCE study [35]. In our post hoc power calculation based on the distribution of chronotype in the same age group in India [3], our sample size $(\mathrm{N}=1916)$ allowed us to generate a statistical power of $100 \%$.

In this exploratory analysis, we first created a directed acyclic graph (DAG) based on a priori evidence of relationships of the living conditions and socioenvironmental factors either with chronotype or with sleep behaviour. Based on the DAG, we assessed the bivariate relationship between each of the independent variables (residential domicile, a smoker at home, indoor condition of the house, cooking media, having a separate kitchen, and any factory/workshop near the house, parental education, number of siblings, family type, having a pet, taking care, or playing with the pet, assisting parents in farming, and playing outside) and chronotypes using Spearman's rank-order correlation with Sidak's correction. We then constructed a multivariable multinomial regression model for all those independent variables which were (i) either associated with chronotype in the correlation analysis or (ii) if there was any previous evidence of such association. Morning type (MT) was considered as the base outcome in the multivariable model. Sex was included in the model as a covariate. The model building included a step-backward algorithm, and the explanatory variables were retained in the model if (i) they were associated with chronotype in the bivariate analyses $(p<0.05)$, (ii) modified the estimates of the remaining variables by more than $10 \%$, or (iii) found to be associated with chronotype in previous studies. The goodness of fit of the logistic models was tested using a generalized Hosmer-Lemeshow goodness-of-fit test [37] and Akaike's information criteria (AIC) [38]. We also assessed any multicollinearity between the independent variables by estimating the variance inflation factor (VIF).

Additionally, we performed some secondary analyses. First, we repeated the analyses stratifying by sex. Secondly, we constructed a negative binomial regression model between rMEQ total score as a count variable and all the abovementioned independent variables that were retained in the multinomial logistic model to observe homogeneity between 
results using categorical and continuous approaches to chronotype. All analyses were performed in Stata V.15.1 (StataCorp, College Station, TX, USA). The present study has been performed in accordance with the Strengthening the Reporting of Observational Studies in Epidemiology (STROBE) guidelines [39].

\section{Results}

\subsection{Demographics}

The demographics, living conditions, and socioenvironmental factors of the study population are summarised in Table 1 . Nearly half $(46.5 \%)$ of the participants were girls. More than $55 \%$ of the participants belonged to an intermediate chronotype, followed by morning types, with evening types being the least frequent. Over half of the participants resided in rural areas, followed by suburban and urban areas. Nearly two thirds of the participants reported having at least one family member who smoked, and more than one third of the population reported being exposed to SHS at home. Liquefied petroleum gas (LPG) was used as the major cooking medium among the houses of participants. Most of the participants had either of their parents graduate from a college or university, while one third of participants had an education level less than or equal to primary school, with parental education up to high-school level being the least frequent. About half of the participants had a pet at home, and only one fifth assisted their parents in farming.

Table 1. Demographic profile of study participants according to chronotype.

\begin{tabular}{|c|c|c|c|c|}
\hline Characteristics & $\begin{array}{c}\text { Total } \\
(\mathrm{N}=1916)\end{array}$ & $\begin{array}{l}\text { Morning Type } \\
\quad(\mathrm{N}=435)\end{array}$ & $\begin{array}{l}\text { Intermediate Type } \\
\quad(\mathrm{N}=1104)\end{array}$ & $\begin{array}{l}\text { Evening Type } \\
\quad(\mathrm{N}=377)\end{array}$ \\
\hline \multicolumn{5}{|l|}{ Sex } \\
\hline Girl & $891(46.5)$ & $211(48.5)$ & $516(46.7)$ & $164(43.5)$ \\
\hline Boy & $1025(53.5)$ & $224(51.5)$ & $588(53.3)$ & $213(56.5)$ \\
\hline \multicolumn{5}{|l|}{ Residential domicile } \\
\hline Rural & $1039(54.2)$ & $321(73.8)$ & $589(53.4)$ & $129(34.2)$ \\
\hline Nonindustrial suburban & $284(14.8)$ & $55(12.6)$ & $166(15.0)$ & $63(16.7)$ \\
\hline Industrial suburban & $165(8.6)$ & $24(5.5)$ & $116(10.5)$ & $25(6.6)$ \\
\hline Urban & $428(22.3)$ & $35(8.1)$ & $233(21.1)$ & $160(42.4)$ \\
\hline Exposure to second-hand smoke at home & $673(37.9)$ & $177(44.5)$ & $381(37.1)$ & $115(32.6)$ \\
\hline \multicolumn{5}{|l|}{ Indoor condition } \\
\hline Poor sunlight, ventilation, and cleanliness & $456(25.8)$ & $133(35.1)$ & $266(26.0)$ & $57(15.8)$ \\
\hline $\begin{array}{c}\text { Adequate sunlight, ventilation, and } \\
\text { cleanliness }\end{array}$ & $545(30.9)$ & $107(28.2)$ & $336(32.8)$ & $102(28.2)$ \\
\hline $\begin{array}{c}\text { Plentiful sunlight, ventilation, and } \\
\text { cleanliness }\end{array}$ & $765(43.3)$ & $139(36.7)$ & $423(41.3)$ & $203(56.1)$ \\
\hline \multicolumn{5}{|l|}{ Cooking media } \\
\hline Liquefied petroleum gas (LPG) & $1076(56.9)$ & $163(37.9)$ & $616(56.5)$ & $297(80.1)$ \\
\hline Biomass fuel & $338(17.9)$ & $127(29.5)$ & $179(16.4)$ & $32(8.6)$ \\
\hline LPG+biomass fuel & $478(25.3)$ & $140(32.6)$ & $296(27.1)$ & $42(11.3)$ \\
\hline Having a separate kitchen at home & $1442(76.7)$ & $323(76.2)$ & $822(75.8)$ & $297(80.1)$ \\
\hline $\begin{array}{l}\text { Any factory that emanates noise, dust, } \\
\text { fumes near home }\end{array}$ & $272(14.6)$ & $57(13.5)$ & $167(15.5)$ & $48(13.1)$ \\
\hline A smoker at home & $1106(59.5)$ & $257(61.6)$ & $651(60.6)$ & $198(53.8)$ \\
\hline \multicolumn{5}{|l|}{ Parental education } \\
\hline Illiterate & $205(11.9)$ & $75(19.8)$ & $108(10.9)$ & $22(6.4)$ \\
\hline Up to primary & $317(18.5)$ & $101(26.7)$ & $188(18.9)$ & $28(8.1)$ \\
\hline Up to high school & $248(14.4)$ & $59(15.6)$ & $149(15.0)$ & $40(11.6)$ \\
\hline College/university & $947(55.2)$ & $143(37.8)$ & $548(55.2)$ & $256(74.0)$ \\
\hline
\end{tabular}


Table 1. Cont.

\begin{tabular}{|c|c|c|c|c|}
\hline Characteristics & $\begin{array}{c}\text { Total } \\
(\mathrm{N}=1916)\end{array}$ & $\begin{array}{l}\text { Morning Type } \\
\quad(\mathrm{N}=435)\end{array}$ & $\begin{array}{l}\text { Intermediate Type } \\
\quad(\mathrm{N}=1104)\end{array}$ & $\begin{array}{l}\text { Evening Type } \\
\quad(N=377)\end{array}$ \\
\hline \multicolumn{5}{|l|}{ Siblings } \\
\hline No sibling & $310(17.8)$ & $44(10.6)$ & $174(17.4)$ & $92(28.1)$ \\
\hline One sibling & 907 (52.2) & $206(49.9)$ & $530(53.2)$ & $171(52.1)$ \\
\hline Two or more siblings & $521(30.0)$ & $163(39.5)$ & $293(29.4)$ & $65(19.8)$ \\
\hline \multicolumn{5}{|l|}{ Family type } \\
\hline Nuclear & $1116(59.7)$ & $276(64.9)$ & $618(57.4)$ & $222(60.7)$ \\
\hline Joint & $752(40.3)$ & $149(35.1)$ & $459(42.2)$ & $144(39.3)$ \\
\hline Having a pet at home & $890(47.8)$ & $255(60.4)$ & $494(46.0)$ & $141(38.5)$ \\
\hline Taking care of pet & $564(31.0)$ & $154(37.6)$ & $307(29.4)$ & $103(28.5)$ \\
\hline Assisting family in farming & $389(20.3)$ & $143(32.9)$ & $212(19.2)$ & $34(9.0)$ \\
\hline Playing outside & $1294(68.4)$ & $296(68.8)$ & $743(68.2)$ & $255(68.2)$ \\
\hline
\end{tabular}

Data presented as frequency (percentage) unless otherwise listed.

\subsection{Association between the Socioenvironmental Factors and Chronotype}

The correlations between the studied chronotype and living condition/socioenvironmental factors have been presented in Table 2. We observed that residential domicile, indoor condition, and parental education were inversely associated (rho $[\rho]$ value range: -0.29 to $-0.16 ; p<0.001$ ) with chronotype, i.e., residing in urban areas, better indoor condition, and higher parental education were associated with higher eveningness. On the contrary, the use of biomass and mixed (biomass+LPG) cooking media, having a sibling, having a pet at home, and assisting parents in farming were significantly ( $\rho$ value range: 0.13 to $0.25 ; p<0.001$ ) associated with higher morningness. Among the independent variables, residential domicile, and cooking media, parental education, having a sibling, having a pet at home, and assisting parents in farming were found to have higher interclass correlation than other socioenvironmental factors.

\subsection{Multivariate Analyses between Socioenvironmental Factors and Chronotype}

In Table 3, we observed that residential domicile was significantly associated with chronotype; the probability of being evening chronotype rather than being morning type was nearly 6 times higher among those living in urban areas than those living in the rural areas (relative risk ratio [RRR]: 5.8; 95\% confidence interval [95\% CI]: 3.4-9.9). Similarly, compared to living in rural areas, living in urban areas was associated with a two-fold higher relative risk (RRR: 2.5; 95\% CI: 1.6-3.9) of being intermediate type than being a morning type. Compared to LPG, the use of biomass and mixed (LPG+biomass) cooking media were also associated with higher morningness compared to eveningness. Having a smoker at home was marginally associated with a higher relative risk of being intermediate type (RRR: 1.3; 95\% CI: 1.0-1.6) but not evening type. Parental education equal to or higher than a college was associated with eveningness (RRR: 2.5 ; 95\% CI: $1.4-4.4$ ) compared to those whose parents were illiterate. The association was also consistent, but to a lesser extent, among the intermediate type (RRR: 1.8; 95\% CI: 1.2-2.7). Assisting parents in farming was found to be associated with greater morningness. Other factors such as exposure to SHS at home, indoor condition of the house, having a separate kitchen, any factory/workshop near the house, number of siblings, family type, having a pet, taking care, or playing with the pet, and playing outside were not found to be significantly associated with chronotype. 
Table 2. Correlation between living conditions/socioenvironmental factors and chronotype.

\begin{tabular}{|c|c|c|c|c|c|c|c|c|c|c|c|c|c|c|c|}
\hline & 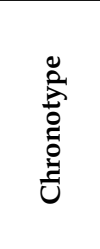 & 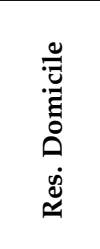 & 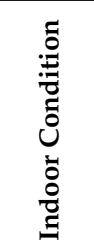 & 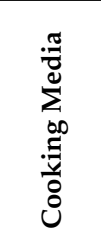 & 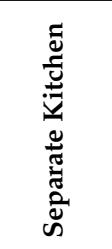 & 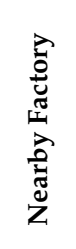 & 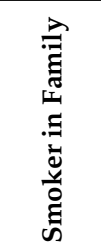 & 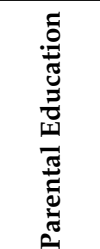 & $\begin{array}{l}\stackrel{\infty}{0} \\
\stackrel{\infty}{0} \\
\stackrel{0}{0}\end{array}$ & 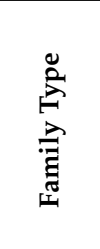 & 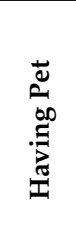 & 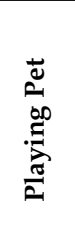 & 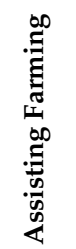 & 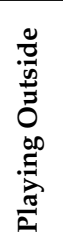 & $p$ value \\
\hline Chronotype & 1 & & & & & & & & & & & & & & \\
\hline Res. domicile & -0.29 & 1 & & & & & & & & & & & & & \\
\hline Indoor condition & -0.16 & 0.25 & 1 & & & & & & & & & & & & \\
\hline Cooking media & 0.25 & -0.41 & -0.23 & 1 & & & & & & & & & & & \\
\hline Separate kitchen & -0.05 & -0.11 & 0.16 & -0.09 & 1 & & & & & & & & & & -0.01 \\
\hline Nearby factory & 0.002 & 0.04 & -0.02 & 0.04 & -0.07 & 1 & & & & & & & & & \\
\hline Smoker in family & 0.06 & -0.14 & -0.14 & 0.13 & 0.03 & 0.06 & 1 & & & & & & & & \\
\hline Parental education & -0.25 & 0.41 & 0.28 & -0.36 & 0.11 & 0.03 & -0.16 & 1 & & & & & & & \\
\hline Siblings & 0.16 & -0.31 & -0.24 & 0.35 & -0.15 & 0.04 & 0.07 & -0.38 & 1 & & & & & & \\
\hline Family type & -0.02 & 0.02 & -0.03 & -0.06 & -0.001 & 0.06 & 0.09 & 0.07 & -0.04 & 1 & & & & & $-<0.001$ \\
\hline Having pet & 0.13 & -0.22 & -0.15 & 0.31 & 0.01 & 0.05 & 0.18 & -0.21 & 0.22 & 0.08 & 1 & & & & \\
\hline Playing pet & 0.08 & -0.11 & -0.08 & 0.21 & -0.03 & 0.04 & 0.14 & -0.12 & 0.16 & 0.07 & 0.72 & 1 & & & \\
\hline Assisting farming & 0.20 & -0.28 & -0.15 & 0.37 & 0.02 & 0.04 & 0.13 & -0.23 & 0.27 & -0.06 & 0.34 & 0.31 & 1 & & \\
\hline Playing outside & 0.01 & 0.12 & -0.08 & 0.07 & -0.07 & 0.06 & 0.05 & -0.04 & 0.01 & 0.02 & 0.09 & 0.13 & 0.10 & 1 & \\
\hline
\end{tabular}

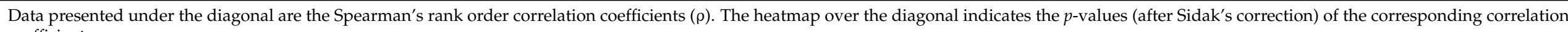
coefficients. 
Table 3. Association between living conditions/socioenvironmental factors and chronotype considering morning type as the base outcome in the multinomial logistic regression model.

\begin{tabular}{|c|c|c|}
\hline \multirow{2}{*}{ Factors } & \multicolumn{2}{|c|}{ RRR $(95 \% \mathrm{CI})$} \\
\hline & Intermediate-Type & Evening-Type \\
\hline \multicolumn{3}{|l|}{ Sex } \\
\hline Boy & Ref & Ref \\
\hline Girl & $1.3(1.0-1.7)$ & $1.7(1.2-2.3)$ \\
\hline \multicolumn{3}{|l|}{ Residential domicile } \\
\hline Rural & Ref & Ref \\
\hline Nonindustrial suburban & $1.2(0.8-1.8)$ & $1.7(1.0-2.7)$ \\
\hline Industrial suburban & $2.2(1.3-3.7)$ & $2.5(1.3-4.7)$ \\
\hline Urban & $2.5(1.6-3.9)$ & $5.8(3.4-9.9)$ \\
\hline \multicolumn{3}{|l|}{ Cooking media } \\
\hline $\begin{array}{l}\text { Liquefied petroleum gas } \\
\text { (LPG) }\end{array}$ & Ref & Ref \\
\hline Biomass fuel & $0.7(0.5-1.0)$ & $0.4(0.3-0.8)$ \\
\hline LPG+biomass fuel & $0.9(0.6-1.2)$ & $0.4(0.3-0.7)$ \\
\hline A smoker at home & $1.3(1.0-1.6)$ & $1.2(0.9-1.7)$ \\
\hline \multicolumn{3}{|l|}{ Parental education } \\
\hline Illiterate & Ref & Ref \\
\hline Up to primary & $1.2(0.8-1.8)$ & $0.9(0.5-1.7)$ \\
\hline Up to high school & $1.5(1.0-2.3)$ & $1.8(0.9-3.4)$ \\
\hline College/university & $1.8(1.2-2.7)$ & $2.5(1.4-4.4)$ \\
\hline Assisting parents in farming & $0.7(0.5-0.9)$ & $0.6(0.3-0.9)$ \\
\hline
\end{tabular}

Data are presented as relative risk ratios (RRR) and 95\% confidence interval (95\% CI) unless otherwise stated. All factors were entered in a single regression model. Values in bold are significant at $p<0.05$.

\subsection{Stratification Analysis by Sex}

After stratifying by sex, living in industrial suburban and urban areas were found to be associated with higher eveningness among the boys, whereas living in industrial suburban areas was associated with higher eveningness among the girls (Table 4). Compared to LPG, the use of biomass and mixed-type cooking media (LPG+biomass) was found to be associated with higher morningness than eveningness among the girls. Having a smoker at home was associated with a higher probability of being intermediate type than morning type among the boys, but no association was observed among girls. Compared to girls whose parents were illiterate, those whose parents attended a college/university had a twofold (RRR: 2.0; 95\% CI: 1.1-3.6) and four-fold (RRR: 3.9; 95\% CI: 1.5-9.9) higher probability of being intermediate and evening types, respectively, than morning type. Assisting parents in farming was associated with higher morning type than the intermediate type (RRR: 0.4; $95 \%$ CI: 0.3-0.7) among girls, but no association was found among boys.

\subsection{Sensitivity Analysis Using rMEQ Total Score as the Dependent Variable}

Taking the total rMEQ score as the outcome in the negative binomial model, we found these results were similar to results where we used chronotypes as categories. Being a girl was marginally associated with eveningness. Living in industrial suburbs and urban areas were associated with a lower total rMEQ score depicting a higher probability of eveningness (Table 5). Use of biomass and mixed-type (LPG+biomass) cooking media were associated with higher morningness. Furthermore, higher parental education was associated with higher eveningness ( $\beta$ : $-0.05 ; 95 \% \mathrm{CI}:-0.10-0.01$ ) among the participants. Assisting parents in farming was found to be marginally $(p=0.06)$ associated with higher morningness among the participants ( $\beta$ : $0.03 ; 95 \% \mathrm{CI}:-0.001-0.07)$. Overall, we observed that most of the factors, which were associated with chronotype, were also consistent when related to the total rMEQ score, indicating homogeneity between rMEQ total score and chronotypes. 
Table 4. Association between living conditions/socioenvironmental factors and chronotype, stratified by sex, considering morning type as the base outcome in a multinomial logistic regression model.

\begin{tabular}{|c|c|c|c|c|}
\hline \multirow{2}{*}{ Factors } & \multicolumn{2}{|c|}{ Boys } & \multicolumn{2}{|c|}{ Girls } \\
\hline & Intermediate Type & Evening Type & Intermediate Type & Evening Type \\
\hline \multicolumn{5}{|l|}{ Residential domicile } \\
\hline Rural & Ref & Ref & Ref & Ref \\
\hline Nonindustrial suburban & $1.7(1.0-2.7)$ & $1.2(0.6-2.4)$ & $0.8(0.4-1.8)$ & $2.2(0.9-5.0)$ \\
\hline Industrial suburban & $1.6(0.8-3.3)$ & $2.6(1.0-6.5)$ & $3.2(1.5-6.6)$ & $2.8(1.1-7.2)$ \\
\hline Urban & $3.7(2.1-6.3)$ & $7.7(4.1-14.4)$ & $1.3(0.5-3.7)$ & $2.7(0.9-8.2)$ \\
\hline \multicolumn{5}{|l|}{ Cooking media } \\
\hline Liquefied petroleum gas (LPG) & Ref & Ref & Ref & Ref \\
\hline Biomass fuel & $0.6(0.3-1.1)$ & $0.7(0.3-1.5)$ & $0.6(0.3-1.0)$ & $0.3(0.1-0.7)$ \\
\hline LPG+Biomass fuel & $1.2(0.7-2.0)$ & $0.6(0.3-1.2)$ & $0.6(0.4-0.9)$ & $0.3(0.1-0.5)$ \\
\hline A smoker at home & $1.5(1.0-2.1)$ & $1.2(0.8-1.9)$ & $1.1(0.7-1.6)$ & $1.1(0.7-2.0)$ \\
\hline \multicolumn{5}{|l|}{ Parental education } \\
\hline Illiterate & Ref & Ref & Ref & Ref \\
\hline Up to primary & $1.4(0.8-2.6)$ & $0.9(0.4-2.3)$ & $1.1(0.6-1.8)$ & $0.8(0.3-2.2)$ \\
\hline Up to high school & $1.0(0.5-1.9)$ & $1.2(0.5-3.0)$ & $2.2(1.1-4.3)$ & $2.1(0.7-6.3)$ \\
\hline College/university & $1.6(0.9-2.8)$ & $1.6(0.7-3.4)$ & $2.0(1.1-3.6)$ & $3.9(1.5-9.9)$ \\
\hline Assisting parents in farming & $0.9(0.6-1.4)$ & $0.6(0.3-1.1)$ & $0.4(0.3-0.7)$ & $0.6(0.2-1.5)$ \\
\hline
\end{tabular}

Data are presented as relative risk ratios (RRR) and $95 \%$ confidence interval $(95 \% \mathrm{CI})$ unless otherwise stated. All factors were entered in a single regression model. Values in bold are significant at $p<0.05$.

Table 5. Associations between living conditions/socioenvironmental factors and total rMEQ score.

\begin{tabular}{|c|c|}
\hline Factors & $\beta(95 \% \mathrm{CI})$ \\
\hline \multicolumn{2}{|l|}{ Sex } \\
\hline Boy & Ref \\
\hline Girl & $-0.03(-0.05-0.0002)$ \\
\hline \multicolumn{2}{|l|}{ Residential domicile } \\
\hline Rural & Ref \\
\hline Nonindustrial suburban & $-0.03(-0.0-0.01)$ \\
\hline Industrial suburban & $-0.06(-0.11--0.02)$ \\
\hline Urban & $-0.14(-0.18--0.10)$ \\
\hline \multicolumn{2}{|l|}{ Cooking media } \\
\hline Liquefied petroleum gas (LPG) & Ref \\
\hline Biomass fuel & $0.06(0.02-0.10)$ \\
\hline LPG+Biomass fuel & $0.06(0.03-0.09)$ \\
\hline A smoker at home & $-0.02(-0.05-0.003)$ \\
\hline \multicolumn{2}{|l|}{ Parental education } \\
\hline Illiterate & Ref \\
\hline Up to primary & $0.007(-0.04-0.05)$ \\
\hline Up to high school & $-0.04(-0.08-0.01)$ \\
\hline College/university & $-0.05(-0.10--0.01)$ \\
\hline Assisting family in farming & $0.03(-0.001-0.07)$ \\
\hline
\end{tabular}

\section{Discussion}

\subsection{Summary of the Findings and Its Contextual Relevance}

To our knowledge, this is the first study to explore the relationship between chronotype and living conditions and socioenvironmental factors. Our result shows that residential domicile, cooking media, having a smoker at home, parental education, and assisting parents in farming are some of the less-studied determinants of chronotype, particularly in adolescents. 
In our study, living in urban areas compared to rural areas was associated with higher eveningness, a finding comparable to previous studies using Indian samples [8,40,41]. The effect was consistent, but to a lesser extent, among those living in industrialized suburbs. Chronotype is dependent on several socioenvironmental aspects including ambient light and temperature [1,42]. Socioecological models explain that urbanization propels humans towards an artificial environment, e.g., controlled temperature and light, rather than a natural environment $[43,44]$, which may result in a lesser exposure to natural light in the morning and greater exposure to artificial evening light that can foster eveningness $[1,45]$. Secondly, compared to a rural lifestyle, an urban lifestyle can offer various nocturnal leisure activities which lead to more evening preference [8]. Thirdly, compared to rural areas, the ambient environment in industrialized suburbs and urban areas constitutes several factors such as higher noise emanating from traffic and industrial sources and higher artificial light at night (ALAN), which are known perturbations of sleep and circadian disruption $[18,45]$. However, there is still a lack of direct causal evidence of the association between urbanization and eveningness, and more epidemiological studies are needed to explore a plausible relationship.

As compared to LPG use, using biomass cooking and biomass mixed-type cooking media was significantly associated with higher morningness, particularly among girls. LPG is a readily accessible medium that requires less time for cooking than using other biomass cooking media. Moreover, in developing countries like India, adolescents, particularly girls in rural areas, assist their parents in household chores including cooking [46], as observed in our study. A recent study showed that household air pollution due to solid fuel combustion was associated with poor sleep among the elderly [22]. Furthermore, although we did not observe any association between indoor conditions and chronotype in our study, indoor air quality (such as odour, airflow, and improper ventilation) was also found to be associated with poor sleep quality and increased risk of sleep apnoea [14-17]. Reducing the use of solid fuel was observed to improve respiratory and sleep symptoms in children [23]. Finally, biomass is typically stored outside of living spaces, and its supply to the kitchen can increase time spent outdoors, which may advance the chronotype if occurring during the first half of the day [9]. However, it is not well understood whether the advancement of such chronotype is driven by a biological clock or is influenced by family obligations. Quantitative assessment of chronotype through a Munich chronotype questionnaire (MCTQ) [47] might be helpful in assessing whether there is social jetlag (misalignment of biological and social time) among the adolescents and thus may confirm the aforementioned argument.

In our study, having a smoker at home was found to be associated with a lower probability of being morning type than intermediate type. It is known that secondary smoke exposure can change sleep-wake patterns to a great extent, with insufficient rest/sleep observed among nonsmokers exposed to secondary smoke [20,21] and increased severity of insomnia [20,48,49]. A recent meta-analysis also suggested that self-reported exposure to SHS was associated with the increased odds of short sleep duration, poor sleep quality, and excessive daytime sleepiness [19]. The sleep pattern and efficiency of sleep may be disturbed by nicotine-induced release of dopamine and serotonin, sleep-regulating neurotransmitters [48]. However, we have not collected data on sleep habits (bedtime and getting up, time spent sleeping, etc.) that could be provide a more objective understanding about their sleep behaviour than the chronotype. With a smaller percentage of those having a smoker at home among evening-type participants than the other two chronotypes, it may be possible that the tendency towards being an intermediate type in SHS-exposed participants was not necessarily related to exposure to nicotine and by-products but rather other unobserved perturbations which warrant further investigation.

We found that higher parental education was associated with higher eveningness among adolescents. Education is often used as a proxy for socioeconomic status [50,51], and it has been reported that higher educational qualification is directly associated with better socioeconomic conditions [50] and lifestyle conditions [52]. Therefore, it can be assumed 
that adolescents of highly educated parents are socially and culturally more exposed to evening-oriented activities than adolescents whose parents had lower educational qualifications. However, there could be other unobserved factors associated with higher parental education which could influence more eveningness among their children. In this study, the association between parental education and eveningness was present only among girls living in rural areas. Although such gender-based variation is not well understood, one plausible explanation could be the possibility that highly educated parents exercise less parental control over their children's night-time activities (reading, working on screens, etc.). However, we did not assess these variables systematically in this study.

Children living in rural areas directly assist their parents in farming or provide auxiliary support in farming or such activities. In subtropical countries like India, farming activities usually start early in the morning to avoid mid-day heat [41]; therefore, morning orientation is common among farmers in rural areas. One recent study on farm adolescents between 11 and 16 years of age showed that 30\% of adolescents had inadequate sleep compared to nonfarm adolescents [34]. Children from a farming background typically follow family practice and are often more morning oriented than those from nonfarming families. One plausible explanation of this association can be drawn in light of day-time physical activity. Some studies suggest that day-time physical exercise [53] as well as longer duration of exercise [54] can actually advance the circadian phase in humans. Farming can be considered as a homologous situation to that of prolonged day-time physical activity, particularly in Indian rural areas, which might induce a similar phase advancement in our study population. However, whether such morningness among rural adolescents is propelled by their biological clock or due to social constraints (such as family and economic condition, farm operation, etc.) is not conclusive and needs further exploration.

\subsection{Societal and Psychological Implications}

The results of our study describe, for the first time, evidence of an understudied potential association between socioenvironmental factors and chronotypes of adolescents. The results also describe the importance of these factors as important influencers of chronotype, particularly in adolescents, and might help chronobiologists, psychologists, and social science researchers to identify plausible attributing factors while assessing individual sleep and activity. Our finding also advocates the importance of more empirical research on this topic to explore unobserved determinants of circadian typology.

\subsection{Strengths and Limitations}

One of the strengths of this study is its large sample size, encompassing a widely distributed territory that covered rural, suburban, and urban areas. Secondly, we assessed several novel factors that have not been investigated systematically. However, our studies have some limitations that should be kept in mind. The cross-sectional design of this study does not allow us to draw any causal associations between the studied factors and chronotype. Another limitation of our study is that we could not observe social jetlag. Although we had previously observed a moderate-high consistency of rMEQ score in a subset of this population who lived in rural and urban areas (Cronbach's $\alpha 0.76$ and 0.75, respectively for rural and urban population) [3], we cannot rule out the possible influence of social jetlag on one's preference to sleep and activity. Additionally, we could not perform any objective measurement of the sleep-wakefulness cycle or diurnal activities of the participants which could have provided substantial support to our results. Though our present study opens several dimensions regarding the possible role of socioenvironmental aspects in modulating the chronotype of individuals, future studies that include hourly sleep measure and other objective variables related to diurnal activity (e.g., actigraphy) and habits would help explain such kind of composite association between chronotype and socioenvironmental factors, and chronotype. 


\section{Conclusions}

We may conclude that in addition to well-known socioenvironmental determinants of chronotype, several other previously unrecognized socioenvironmental factors are also associated with chronotype, particularly in adolescents. More longitudinal qualitative and quantitative epidemiological studies that follow their passage to adulthood are warranted.

Author Contributions: Conceptualization, P.H., S.G.M., S.M. (Saibal Moitra), and S.M. (Subhabrata Moitra); Formal analysis, S.M. (Subhabrata Moitra); Funding acquisition, A.A. and K.S.J.; Investigation, P.H., S.D., S.G.M., and S.M. (Subhabrata Moitra); Methodology, P.H., S.D., S.G.M., S.M. (Saibal Moitra), and S.M. (Subhabrata Moitra); Project administration, P.H., S.D., D.C., S.G.M., and S.M. (Subhabrata Moitra); Resources, P.H., S.M. (Saibal Moitra) and S.M. (Subhabrata Moitra); Software, S.M. (Subhabrata Moitra); Supervision, S.M. (Subhabrata Moitra); Validation, A.A., D.C., P.L. and S.M. (Subhabrata Moitra); Visualization, S.M. (Subhabrata Moitra); Writing-original draft, P.H. and S.M. (Subhabrata Moitra); Writing—review and editing, P.H., S.D., A.A., K.S.J., D.C., S.G.M., S.M. (Saibal Moitra), P.L., and S.M. (Subhabrata Moitra). All authors have read and agreed to the published version of the manuscript.

Funding: An internal research support grant of Allergy and Asthma Research Centre, Kolkata was received for the PERFORMANCE Study (to S.M. (Saibal Moitra)). A.A. is supported by the Spanish Ministry of Economy, Industry, and Competitiveness (Grant PSI2015-65026; MINECO/FEDER/UE). K.S.J. is supported by the Polish Ministry of Science and Higher Education (IP2015026774).

Institutional Review Board Statement: The study was conducted according to the guidelines of the Declaration of Helsinki and approved by the Clinical Research Ethics Committee of the Allergy and Asthma Research Centre (CREC-AARC), Kolkata (Approval Id: CREC-AARC-04-2016).

Informed Consent Statement: Since the study participants were minors as per Indian law, informed consent was obtained from parents and appropriate school administrations.

Data Availability Statement: The data presented in this study are available on request from the corresponding author. The data are not publicly available due to sensitive personal information of the minors.

Acknowledgments: On behalf of the PERFORMANCE Study Group. The PERFORMANCE collaborators: Ana Adan (University of Barcelona, Barcelona, Spain), Isabella Annesi-Maesano (INSERM and Sörbonn Université, Paris, France), Arghya Bandyopadhyay (IISER-Kolkata, Kolkata, India), Moumita Biswas (Santipur State General Hospital, Santipur, India), Soumya Bhattacharjee (R.G. Kar Medical College and Hospital, Berhampore, India), Anne-Elie Carsin (ISGlobal, Universitat Pompeu Fabra (UPF) and CIBER Epidemiología y Salud Pública (CIBERESP), Barcelona, Spain), Dwiptirtha Chattopadhyay (Jalpaiguri Institute of Medical Science and Research, Jalpaiguri, India), Judith Garcia-Aymerich (ISGlobal, Universitat Pompeu Fabra (UPF) and CIBER Epidemiología y Salud Pública (CIBERESP), Barcelona, Spain), Atanu Ghosh (Presidency University, Kolkata, India), Konrad S. Jankowski (University of Warsaw, Warsaw, Poland), Manolis Kogevinas (ISGlobal, Universitat Pompeu Fabra (UPF) and CIBER Epidemiología y Salud Pública (CIBERESP), Barcelona, Spain), Santi Gopal Maity (Uluberia College, Uluberia, India), Tarunendu Mapder (Indiana University, Indianapolis, USA), Ritabrata Mitra (Institute of Post Graduate Medical Education and Research (IPGME\&R) and SSKM Hospital, Kolkata, India), Saibal Moitra (Allergy and Asthma Research Centre, Kolkata, India), Subhabrata Moitra (University of Alberta, Edmonton, Canada), Sujoy Saha (BR Singh Hospital, Kolkata, India), and Soumya Sengupta (Charnock Hospital, Kolkata, India). The authors also gratefully thank the administrations of the attended schools for allowing to conduct the study; the students for participating in this study and the parents for their consents.

Conflicts of Interest: The authors declare no conflict of interest.

\section{References}

1. Adan, A.; Archer, S.N.; Hidalgo, M.P.; Di Milia, L.; Natale, V.; Randler, C. Circadian Typology: A Comprehensive Review. Chronobiol. Int. 2012, 29, 1153-1175. [CrossRef]

2. Randler, C.; Prokop, P.; Sahu, S.; Haldar, P. Cross-cultural comparison of seven morningness and sleep-wake measures from Germany, India and Slovakia. Int. J. Psychol. 2015, 50, 279-287. [CrossRef] [PubMed] 
3. Haldar, P.; Bhattacharjee, S.; Maity, S.G.; Debnath, S.; Moitra, S.; Moitra, S. Chronotype assessment of the Bengalese adolescents: An observational study using a Bengali version of the reduced Morningness-Eveningness Questionnaire (rMEQ). Biol. Rhythm Res. 2019, 51, 971-979. [CrossRef]

4. Kalmbach, D.A.; Schneider, L.D.; Cheung, J.; Bertrand, S.J.; Kariharan, T.; Pack, A.I.; Gehrman, P.R. Genetic Basis of Chronotype in Humans: Insights from Three Landmark GWAS. Sleep 2017, 40. [CrossRef] [PubMed]

5. Jones, S.E.; Lane, J.M.; Wood, A.R.; van Hees, V.T.; Tyrrell, J.; Beaumont, R.N.; Jeffries, A.R.; Dashti, H.S.; Hillsdon, M.; Ruth, K.S.; et al. Genome-wide association analyses of chronotype in 697,828 individuals provides insights into circadian rhythms. Nat. Commun. 2019, 10. [CrossRef] [PubMed]

6. Wittmann, M.; Dinich, J.; Merrow, M.; Roenneberg, T. Social jetlag: Misalignment of biological and social time. Chronobiol. Int. 2006, 23, 497-509. [CrossRef]

7. Pilz, R.; Winnebeck, Z. Chronotype and Social Jetlag: A (Self-) Critical Review. Biology 2019, 8, 54. [CrossRef]

8. Tonetti, L.; Sahu, S.; Natale, V. Circadian preference in Italy and India: A comparative study in young adults. Personal. Individ. Differ. 2012, 53, 355-358. [CrossRef]

9. Roenneberg, T.; Kumar, C.J.; Merrow, M. The human circadian clock entrains to sun time. Curr. Biol. 2007, 17, R44-R45. [CrossRef] [PubMed]

10. Miguel, M.; Oliveira, V.C.D.; Pereira, D.; Pedrazzoli, M. Detecting chronotype differences associated to latitude: A comparison between Horne-Östberg and Munich Chronotype questionnaires. Ann. Hum. Biol. 2013, 41, 107-110. [CrossRef] [PubMed]

11. Sani, M.; Refinetti, R.; Jean-Louis, G.; Pandi-Perumal, S.R.; Durazo-Arvizu, R.A.; Dugas, L.R.; Kafensztok, R.; Bovet, P.; Forrester, T.E.; Lambert, E.V.; et al. Daily activity patterns of 2316 men and women from five countries differing in socioeconomic development. Chronobiol. Int. 2015, 32, 650-656. [CrossRef]

12. White, T.M.; Terman, M. Effect of iris pigmentation and latitude on chronotype and sleep timing. Chronobiol. Int. 2003, 20, 1193-1195. [CrossRef]

13. Carvalho, F.G.; Hidalgo, M.P.; Levandovski, R. Differences in circadian patterns between rural and urban populations: An epidemiological study in countryside. Chronobiol. Int. 2014, 31, 442-449. [CrossRef] [PubMed]

14. Shiue, I. Indoor mildew odour in old housing was associated with adult allergic symptoms, asthma, chronic bronchitis, vision, sleep and self-rated health: USA NHANES, 2005-2006. Environ. Sci. Pollut. Res. 2015, 22, 14234-14240. [CrossRef] [PubMed]

15. Mishra, A.K.; van Ruitenbeek, A.M.; Loomans, M.G.L.C.; Kort, H.S.M. Window / door opening-mediated bedroom ventilation and its impact on sleep quality of healthy, young adults. Indoor Air 2018, 28, 339-351. [CrossRef]

16. Lappharat, S.; Taneepanichskul, N.; Reutrakul, S.; Chirakalwasan, N. Effects of Bedroom Environmental Conditions on the Severity of Obstructive Sleep Apnea. J. Clin. Sleep Med. 2018, 14, 565-573. [CrossRef] [PubMed]

17. Lan, L.; Xia, L.; Tang, J.; Zhang, X.; Lin, Y.; Wang, Z. Elevated airflow can maintain sleep quality and thermal comfort of the elderly in a hot environment. Indoor Air 2019, 29, 1040-1049. [CrossRef]

18. Skrzypek, M.; Kowalska, M.; Czech, E.; Niewiadomska, E.; Zejda, J.E. Impact of road traffic noise on sleep disturbances and attention disorders amongst school children living in Upper Silesian Industrial Zone, Poland. Int. J. Occup. Med. Environ. Health 2017, 30, 511. [CrossRef]

19. Safa, F.; Chaiton, M.; Mahmud, I.; Ahmed, S.; Chu, A. The association between exposure to second-hand smoke and sleep disturbances: A systematic review and meta-analysis. Sleep Health 2020, 6, 702-714. [CrossRef]

20. Sabanayagam, C.; Shankar, A. The association between active smoking, smokeless tobacco, second-hand smoke exposure and insufficient sleep. Sleep Med. 2011, 12, 7-11. [CrossRef]

21. Morioka, H.; Jike, M.; Kanda, H.; Osaki, Y.; Nakagome, S.; Otsuka, Y.; Kaneita, Y.; Itani, O.; Higuchi, S.; Ohida, T. The association between sleep disturbance and second-hand smoke exposure: A large-scale, nationwide, cross-sectional study of adolescents in Japan. Sleep Med. 2018, 50, 29-35. [CrossRef]

22. Chen, C.; Liu, G.G.; Sun, Y.; Gu, D.; Zhang, H.; Yang, H.; Lu, L.; Zhao, Y.; Yao, Y. Association between household fuel use and sleep quality in the oldest-old: Evidence from a propensity-score matched case-control study in Hainan, China. Environ. Res. 2020, 191, 110229. [CrossRef]

23. Accinelli, R.A.; Llanos, O.; López, L.M.; Pino, M.I.; Bravo, Y.A.; Salinas, V.; Lazo, M.; Noda, J.R.; Sánchez-Sierra, M.; Zárate, L.; et al. Adherence to reduced-polluting biomass fuel stoves improves respiratory and sleep symptoms in children. BMC Pediatrics 2014, 14. [CrossRef]

24. Parikh, R.; Rao, S.R.; Kukde, R.; O'Connor, G.T.; Patel, A.; Hibberd, P.L. Assessing the Respiratory Effects of Air Pollution from Biomass Cookstoves on Pregnant Women in Rural India. Int. J. Environ. Res. Public Health 2020, 18, 183. [CrossRef]

25. Chakraborty, D.; Mondal, N.K. Hypertensive and toxicological health risk among women exposed to biomass smoke: A rural Indian scenario. Ecotoxicol. Environ. Saf. 2018, 161, 706-714. [CrossRef]

26. Pande, B.; Parveen, N.; Parganiha, A.; Pati, A.K. Shortening of sleep length and delayed mid-sleep on free days are the characteristic features of predominantly morning active population of Indian teenagers. Sleep Biol. Rhythm. 2018, 16, 431-439. [CrossRef]

27. Randler, C.; Bilger, S. Associations among Sleep, Chronotype, Parental Monitoring, and Pubertal Development among German Adolescents. J. Psychol. 2009, 143, 509-520. [CrossRef] [PubMed] 
28. Martinez, S.M.; Tschann, J.M.; Butte, N.F.; Gregorich, S.E.; Penilla, C.; Flores, E.; Pasch, L.A.; Greenspan, L.C.; Deardorff, J. Sleep duration in Mexican American children: Do mothers' and fathers' parenting and family practices play a role? J. Sleep Res. 2019, 28, e12784. [CrossRef] [PubMed]

29. Ogi, H.; Nakamura, D.; Ogawa, M.; Nakamura, T.; Izawa, K. Associations between Parents' Health Literacy and Sleeping Hours in Children: A Cross-Sectional Study. Healthcare 2018, 6, 32. [CrossRef]

30. Dubois-Comtois, K.; Pennestri, M.-H.; Bernier, A.; Cyr, C.; Godbout, R. Family environment and preschoolers' sleep: The complementary role of both parents. Sleep Med. 2019, 58, 114-122. [CrossRef] [PubMed]

31. Breitenstein, R.S.; Doane, L.D.; Clifford, S.; Lemery-Chalfant, K. Children's sleep and daytime functioning: Increasing heritability and environmental associations with sibling conflict. Soc. Dev. 2018, 27, 967-983. [CrossRef]

32. Xu, H.; Wen, L.M.; Hardy, L.L.; Rissel, C. Associations of outdoor play and screen time with nocturnal sleep duration and pattern among young children. Acta Paediatr. 2016, 105, 297-303. [CrossRef]

33. Lin, Y.; Borghese, M.M.; Janssen, I. Bi-directional association between sleep and outdoor active play among 10-13 year olds. BMC Public Health 2018, 18. [CrossRef]

34. Janssen, I.; Berg, R.L.; Marlenga, B.; Pickett, W. Sleep in Farm Adolescents. J. Rural Health 2018, 35, 436-441. [CrossRef]

35. Bhattacharjee, S.; Haldar, P.; Gopal Maity, S.; Debnath, S.; Moitra, S.; Saha, S.; Mitra, R.; Annesi-Maesano, I.; Garcia-Aymerich, J.; Moitra, S. Prevalence and Risk Factors of Asthma and Allergy-Related Diseases among Adolescents (PERFORMANCE) study: Rationale and methods. ERJ Open Res. 2018, 4, 00034-2018. [CrossRef]

36. Adan, A.; Almirall, H. Horne \& Östberg morningness-eveningness questionnaire: A reduced scale. Personal. Individ. Differ. 1991, 12, 241-253. [CrossRef]

37. Fagerland, M.W.; Hosmer, D.W. A Generalized Hosmer-Lemeshow Goodness-of-Fit Test for Multinomial Logistic Regression Models. Stata J. Promot. Commun. Stat. Stata 2018, 12, 447-453. [CrossRef]

38. Salkind, N.J. (Ed.) Encyclopedia of Measurement and Statistics; Sage Publications, Inc.: Thousand Oaks, CA, USA, 2011. [CrossRef]

39. von Elm, E.; Altman, D.G.; Egger, M.; Pocock, S.J.; Gøtzsche, P.C.; Vandenbroucke, J.P. The Strengthening the Reporting of Observational Studies in Epidemiology (STROBE) statement: Guidelines for reporting observational studies. Lancet 2007, 370 , 1453-1457. [CrossRef]

40. Achari, K.V.; Pati, A.K. Morningness-eveningness preference in Indian school students as function of gender, age and habitat. Biol. Rhythm Res. 2007, 38. [CrossRef]

41. Nag, C.; Pradhan, R.K. Impact of lifestyle on circadian orientation and sleep behaviour. Sleep Biol. Rhythm. 2012, 10, 94-99. [CrossRef]

42. Horzum, M.B.; Randler, C.; Masal, E.; Beşoluk, S..; Önder, İ.; Vollmer, C. Morningness-eveningness and the environment hypothesis-A cross-cultural comparison of Turkish and German adolescents. Chronobiol. Int. 2015, 32, 814-821. [CrossRef] [PubMed]

43. Goldstein, G. Urbanization, Health and Well-Being: A Global Perspective. Statistician 1990, 39, 121. [CrossRef]

44. Lawrence, R.J. Uban Health: An Ecological Perspective. Rev. Environ. Health 1999, 14. [CrossRef] [PubMed]

45. Martin, J.S.; Hébert, M.; Ledoux, É.; Gaudreault, M.; Laberge, L. Relationship of Chronotype to Sleep, Light Exposure, and Work-Related Fatigue in Student Workers. Chronobiol. Int. 2012, 29, 295-304. [CrossRef]

46. Rao, G.P.; Vidya, K.L.; Sriramya, V. The Indian "girl” psychology: A perspective. Indian J. Psychiatry 2015, 57, 212. [CrossRef]

47. Roenneberg, T.; Kuehnle, T.; Juda, M.; Kantermann, T.; Allebrandt, K.; Gordijn, M.; Merrow, M. Epidemiology of the human circadian clock. Sleep Med. Rev. 2007, 11, 429-438. [CrossRef] [PubMed]

48. Khorasanchi, Z.; Bahrami, A.; Avan, A.; Jaberi, N.; Rezaey, M.; Bahrami-Taghanaki, H.; Ferns, G.A.; Ghayour-Mobarhan, M. Passive smoking is associated with cognitive and emotional impairment in adolescent girls. J. Gen. Psychol. 2019, 146, 68-78. [CrossRef]

49. Yolton, K.; Xu, Y.; Khoury, J.; Succop, P.; Lanphear, B.; Beebe, D.W.; Owens, J. Associations Between Secondhand Smoke Exposure and Sleep Patterns in Children. Pediatrics 2010, 125, e261-e268. [CrossRef]

50. Galobardes, B. Indicators of socioeconomic position (part 1). J. Epidemiol. Community Health 2006, 60, 7-12. [CrossRef] [PubMed]

51. Jankovic, S.; Stojisavljevic, D.; Jankovic, J.; Eric, M.; Marinkovic, J. Association of socioeconomic status measured by education, and cardiovascular health: A population-based cross-sectional study. BMJ Open 2014, 4, e005222. [CrossRef]

52. Tubeuf, S.; Jusot, F.; Bricard, D. Mediating Role of Education and Lifestyles in the Relationship between Early-Life Conditions and Health: Evidence from the 1958 British Cohort. Health Econ. 2012, 21, 129-150. [CrossRef] [PubMed]

53. Miyazaki, T.; Hashimoto, S.; Masubuchi, S.; Honma, S.; Honma, K.-I. Phase-advance shifts of human circadian pacemaker are accelerated by daytime physical exercise. Am. J. Physiol. Regul. Integr. Comp. Physiol. 2001, 281, R197-R205. [CrossRef] [PubMed]

54. Buxton, O.M.; Lee, C.W.; L'Hermite-Balériaux, M.; Turek, F.W.; van Cauter, E. Exercise elicits phase shifts and acute alterations of melatonin that vary with circadian phase. Am. J. Physiol. Regul. Integr. Comp. Physiol. 2003, 284, R714-R724. [CrossRef] [PubMed] 